\title{
Performance Benchmarking: A Literature Review And Analysis For Atmospheric Fluidized Bed Combustion Plants
}

\author{
Jack A. Fuller, (E-mail: jfuller@wvu.edu), West Virginia University \\ Robert Bessette, Council of Industrial Boiler Owners \\ Mark Freier, Department of Energy
}

\section{Introduction}

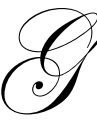

aining and maintaining a competitive edge is the key to success in all walks of life, both on the athletic field and in the boardroom. (The following sections are largely derived from McNair and Leibfried [26]. For additional background information on benchmarking, see Ammons [1], Anderson [2], Baker [3]. Balm [4], Biesada [5] and [6], Bogan and English [7], Camp [8], Campbell [9], Cox and Thompson [10], Cox, Mann, and Samson [11], Das [12], Davies [13], Day [14], Dunn [15], Elmuti [16], Elmuti, Kathawala, and Lloyd [17], Eyrich [18], Fitz-enz [19], Fong and Cheng [20], Fuller and Scherr [21], Henricks [22], Jackman [23], Main [24], McGonagle and Fleming [25], Murray, Zimmerman, and Flaherty [27], O'Mara [28], Puckett and Seigel [29], Quality and Productivity Management Association [30], Ransley [31], Schwartz [32], Sheridan [33], Vaziri [34], and Waston [35].) Tradition and intuition are no replacement for objective external comparison and analysis (i.e., benchmarking). Benchmarking is emerging in leading-edge companies as a tool for obtaining the information needed to support continuous improvement and gain a competitive advantage. Benchmarking embodies the pursuit of excellence, the desire to be the "best of the best".

This research paper will: (1) provide a background on the concept of benchmarking; and (2) present some examples of performance benchmarks for AFBC (atmospheric fluidized bed combustor) steam and power plants resulting from data collected during 1999.

Benchmarking brings an external focus on internal activities, functions, or operations in order to achieve continuous improvement. Starting from an analysis of existing activities and practices within the firm, the objective is to understand existing processes or activities and then to identify an external point of reference or standard by which that activity can be measured or judged.

The ultimate goal is quite simple: To be better than the best; to attain a competitive edge. Stated one way, benchmarking is the continuous process of measuring product, services, and practices against the toughest competitors or those companies recognized as industry leaders. Business success requires fact (not fiction) and analysis (not guesstimates) with a clear ongoing focus on meeting and exceeding customer expectations.

The continuous pursuit of excellence is the underlying and ever-present goal of benchmarking practices. The starting point in achieving excellence is the customer. Whether internal or external to the organization, the customer sets the expectations for performance and is the ultimate judge of its quality.

For benchmarking purposes, a customer is anyone who has a stake or interest in the ongoing operations of the company. World-class performance is dedicated to serving the customer. Well-run companies now see the final customer as just the end-point in a chain of customers. Everyone has a customer at the next process (i.e., where your work goes next). The customer then can be internal or external to the organization. It is anyone who receives the output of our labor or is affected by its quality and timeliness.

Readers with comments or questions are encouraged to contact the authors via email. 
A stakeholder is a broader concept than customer, which indicates that a service or product is being provided as an endpoint in a value chain. Stakeholders include suppliers, owners, employees, and customers. These four groups are dependent on the company for their physical and financial well being.

To attain excellence, a corporation has to move far beyond the basics, looking for ways to improve upon existing products and services. Benchmarking provides management with the tools needed to make the hard decisions about resource allocation and the strategic focus of the organization. It develops a series of objective measures of the success of the company strategy as set against external organizations performing at recognized levels of excellence. Managing a corporation is a brutal competitive struggle to secure and expand the resources committed by its various stakeholders. By benchmarking the company's performance against the expectations of these stakeholders, success can be attained.

In order to establish a benchmark or performance target, individuals or departments must both identify and communicate with their customers. Communication (or direction-setting) is enhanced through the process of establishing internal and external performance benchmarks. Benchmarks cannot be established without a comprehensive understanding of current practice, desired results, and the recognition and acceptance of the changes that will need to occur to meet and exceed those goals. Unfortunately, few individuals or companies are open to continuous change and improvement. Instead, people generally strive to hold on to the present, to put protective tariffs and other fences around themselves to keep change away.

\section{Four Phases of Benchmarking}

Classical benchmarking involves four distinct phases. Phase I is internal assessment of existing practice. It is the comparison of multiple groups within a company that are performing basically the same task. It is applicable in any decentralized or divisionalized company. Phase II involves data gathering. Phase III begins where data collection ends. It is the analysis of the collected information which results in the creation of a "straw man" model, an identification of performance gaps, and their prioritization. Phase IV is the action phase. Methods used to implement change after the benchmarking study are the same as those used in any change process. Communication, a clear set of objectives, measurements that track improvement, and the active participation and perceived value of each participant are the essence of any successful change.

\section{Four Types of Benchmarking}

The four types of benchmarking are: (1) internal, (2) competitive, (3) industry, and (4) best-in-class. Internal benchmarking focuses on the improvement and standardization of internal operations. It is usually used as the first step in an external benchmarking project, but can also be a freestanding event.

Competitive benchmarking is concerned with global measures of performance for a representative sample of companies competing in the same product line. It is not really concerned with discovering processes or structural facts about the competition. Instead, it attempts to discover the relative deployment of resources in certain parts of the business, as well as the effectiveness of those resources. The result is to prioritize those aspects of the business that are underperforming the competition.

When the focus shifts from the measured distribution of resources to a concern with how those resources are structured and managed, it is industry benchmarking. In this case, one looks for trends or patterns in the way specific resources are deployed for a specific industry. "Best in class" benchmarking moves beyond traditional competitive boundaries. By definition, its focus is outside of the firm's industry. This type of benchmarking looks for innovative practices used in a variety of settings to manage the technologies and resources of an organization. The focus here is on organizational issues that separate the top performers in any discipline or industry from the rest. 


\section{Consistent Themes in Benchmarking}

The consistent themes related to benchmarking are continuous improvement, stakeholder interests, and change. Benchmarking is a tool for enacting change, as defined within the philosophy of continuous improvement. The measure of success in the change process is defined by the creation of value in the stakeholder's eyes.

Benchmarking is externally oriented and seeks to gather information about creative ways to restructure the processes and resources of a company to better serve its varied stakeholders' needs. The analysis performed and methods employed in an effective benchmarking study are objective. Benchmarking is a process without an end. Each time it is performed, lessons are learned and improvements made, which highlight the next area needing attention.

\section{Reasons a Company May Not Want to Benchmark}

There are several reasons why a company may not want to engage in a benchmarking effort, including:

1. They want to maintain the status quo.

2. They want to remain where they are, secure in the knowledge they are doing the best they can.

3. Reality checks are not to their liking.

4. Benchmarking will open the company to change and to humility.

5. Finding out your real rank (your comparative competencies) is a sobering lesson.

\section{Benchmarking Work}

The authors analyzed data from a fluidized bed boiler survey distributed during 1999 to begin the process of developing AFBC performance benchmarks. The survey was sent to members of the Council of Industrial Boiler Owners (CIBO), who sponsored the survey, as well as to other firms who had an operating AFBC boiler on-site. The useable response rate to the survey was approximately thirty-five percent, resulting in thirty-five useable surveys to analyze. The survey respondents principally use AFBC technology in steam and power plants ranging in size from a few megawatts (MW) to several hundred MW in size.

There were three primary purposes for the collection and analysis of the data contained in this fluidized bed boiler survey:

1. To start the process of developing atmospheric fluidized bed (AFB) benchmarks on technical, cost, revenue, and environmental issues.

2. To inform AFB owners and operators of contemporary concerns and issues in the industry.

3. To improve decision making in the industry with respect to current and future plant start-ups and ongoing operations.

These three purposes were identified by CIBO leadership and members as being key to improving the operating efficiency and performance of AFBC plants.

As a starting point for a more exhaustive future benchmarking effort, it was decided to focus on three distinct benchmarks: (1) Number of full-time equivalent staff per million megawatt hours, (2) Total gross plant efficiency (expressed as British Thermal Units [BTU's] per gross kilowatt hour, and (3) Percent of time on-line in 1998.

The decision as to which three example benchmarks to develop was made based on extensive discussions with a large sample of FBC owners and operators. The consensus was that this information would be extremely valuable in analyzing their individual operations. In relationship to the above-referenced four types of benchmarks, these would be classified as being examples of the second and third types: Competitive Benchmarks and Industry Benchmarks. In reference to the above four phases of benchmarking, these phases occur within a specific firm. A company would necessarily use aspects of these four phases as they generated the information for the current survey and then utilized the survey benchmark results to improve their firm's performance. 
Attachment 1 contains the various charts showing the results of the analysis performed for these three example benchmarks using the data from the respondent surveys. The AFBC plants of survey responders which were not included in the analysis were: (1) those who indicated that the plant was used for peaking purposes, (2) those plants that were in curtailment for a significant portion of the time in 1998 or 1999, and (3) those plants which produced steam only (since there were only two such respondents). The logic for leaving steam-only generators out of the analysis is that with a sample size of only two, it would be nearly impossible to develop reliable benchmarks for this group. It should be pointed out that unless the respondent indicated specifically that the plant was indeed a peaking unit or was in curtailment, it would be difficult to determine this otherwise and the plant would therefore be included in the analysis. A suggestion for a further study would be to include a response item specifically indicating if the boiler was used for peaking purposes or was in curtailment.

Another issue, which came up in interpreting the survey data, related to those surveys which indicated multiple boilers were contained in the plant. Questions here had to do with whether the other boilers were also FBC units or not and whether they were driving the same turbine. Many times it was difficult to determine whether the data in a particular survey, for those indicating multiple boilers, referred to a particular boiler or was aggregated over all boilers at the site. Again, the recommendation was to include additional clarifying information in a followup study.

Referring to Chart 1 in Attachment 1, this benchmark shows the number of FTE staff per million MWH during calendar year 1998. There were sufficient responses to break the data down into five plant sizes (1-19 MW, 20-49 MW, 50-74 MW, 75-99 MW, and >= $100 \mathrm{MW}$ ) in the left figure and three primary fuel types (coal, culm, and gob) in the right figure. There were nearly enough responses obtained to break down the data into both plant size and primary fuel type simultaneously. (It should be noted that to maintain confidentiality of respondents, there needs to be at least a sample size of three in each category.) It is hoped that the response rate on a recommended follow-up survey can be increased sufficiently to perform such combined analysis. The vertical axis in Chart 1 is in ratio form and the horizontal axis references plant size in the left figure and plant size and type of primary fuel in the right figure.

The left table below displays the benchmark results based on plant size. To interpret the data, it shows, for example, that the average number of FTE staff per million MWH for plants of the $1-19$ MW size was 177.8. The table on the right displays the benchmark results based on plant size and fuel type. To interpret the data in this table, it shows, for example, that the average number of FTE staff per million MWH for plants of the $20-49$ MW size, which burned coal as a primary fuel, was 135.5.

\begin{tabular}{|l|l|}
\hline Plant Size (MW) & Benchmark \\
\hline $1-19$ & 177.8 \\
\hline $20-49$ & 90.3 \\
\hline $50-74$ & 85.1 \\
\hline $75-99$ & 49.2 \\
\hline$\geq 100$ & 41 \\
\hline
\end{tabular}

\begin{tabular}{|l|l|}
\hline $\begin{array}{l}\text { Plant Size (MW) and } \\
\text { Fuel Type }\end{array}$ & Benchmark \\
\hline $20-49 \&$ coal & 135.5 \\
\hline $50-74 \&$ coal & 134.3 \\
\hline $50-74 \&$ gob & 44.6 \\
\hline $75-99 \&$ coal & 40.5 \\
\hline $75-99 \&$ culm & 50.4 \\
\hline $75-99 \&$ gob & 55.6 \\
\hline$\geq 100$ \& coal & 40.4 \\
\hline
\end{tabular}

All of the charts in Attachment 1 are set up the same way. That is, the left figure shows the data based on plant size and the right figure shows the data based on type of primary fuel. The incremental units in both figures in a chart will be the same so that one can readily compare the differences based on plant size and primary fuel type. The displayed values in the charts are simple averages for useable responses in each grouping.

Chart 2 in Attachment 1 shows the total gross plant efficiency in BTU's per gross KWH. As in the pre- 
vious tables, the left table below displays the benchmark results based on plant size. As an example from this table, the average benchmark value for 50-74 MW plants was 12,042 BTU's per gross KWH. You will note that there was insufficient data to develop benchmarks for the 1-19, 20-49, and 75-99 MW plant size ranges. The table on the right displays the benchmark results based on plant size and fuel type. To interpret the data in this table, it shows, for example, that the total gross plant efficiency for plants of the 50-74 MW size, which burned coal as a primary fuel, was 11,186 BTU's per gross KWH.

\begin{tabular}{|l|l|}
\hline Plant Size (MW) & Benchmark \\
\hline $1-19$ & NA \\
\hline $20-49$ & NA \\
\hline $50-74$ & 12,042 \\
\hline $75-99$ & NA \\
\hline$\geq 100$ & 10,643 \\
\hline
\end{tabular}

\begin{tabular}{|l|l|}
\hline $\begin{array}{l}\text { Plant Size (MW) and } \\
\text { Fuel Type }\end{array}$ & Benchmark \\
\hline $50-74$ \& coal & 11,186 \\
\hline $50-74$ \& gob & 11,169 \\
\hline $75-99 \&$ gob & 9,688 \\
\hline$\geq 100 \&$ coal & 10,643 \\
\hline
\end{tabular}

Chart 3 in Attachment 1 shows the percent of time on-line in 1998. As an example from the left table, the average benchmark value for 1-19 MW plants was 89.9 percent. The table on the right displays the benchmark results based on plant size and fuel type. For example, this table shows that the average percent of time on-line in 1998 for plants of the $20-49 \mathrm{MW}$ size, which burned coal as a primary fuel, was 94.7 percent. One observation pertaining to the table on the right is that the data for 50-74 MW plants that burn coal and 75-99 MW plants that burn coal seems unexpectedly low. The author does not have any additional insight as to this occurrence, other than that the few plants in question may have been undergoing, for example, some extended modifications.

\begin{tabular}{|l|l|}
\hline Plant Size (MW) & Benchmark \\
\hline $1-19$ & 89.9 \\
\hline $20-49$ & 94.7 \\
\hline $50-74$ & 85.1 \\
\hline $75-99$ & 88.2 \\
\hline$\geq 100$ & 90.9 \\
\hline
\end{tabular}

\begin{tabular}{|l|l|}
\hline $\begin{array}{l}\text { Plant Size (MW) and } \\
\text { Fuel Type }\end{array}$ & Benchmark \\
\hline 20- 49 \& coal & 94.7 \\
\hline $50-74$ \& coal & 72.5 \\
\hline $50-74$ \& culm & 93.8 \\
\hline $50-74$ \& gob & 94.1 \\
\hline $75-99$ \& coal & 60.7 \\
\hline $75-99$ \& culm & 92.5 \\
\hline $75-99$ \& gob & 98.2 \\
\hline$\geq 100$ \& coal & 90.4 \\
\hline
\end{tabular}

\section{Summary}

The previous section presented benchmark information on three key operational parameters: number of full-time staff, efficiency, and percent of time online. Each of these benchmarks has a significant effect on the product cost. Question: Presented with this information, or similar information on your particular industry or business, how do you use it?

One should start by understanding the benchmarking results. The type of data presented is competitive benchmarks, which were developed from survey forms sent to Atmospheric Fluidized Bed Combustion (AFBC) plants. The data is split into five segments by plant size and also by fuel type, when a sufficient number of samples are available. A minimum of three is required to protect the source of the responses. The results are presented as the average of the responses in each segment. The range of the data is not presented. (Unfortunately, this will limit the analysis to determining if the subject plant is above or below average. The distance from average is difficult to discern. Above average could be the best of the best, below could be the worst of the worst.)

Internal Benchmarking develops the numbers for comparison to the competitive benchmarks. This step would normally be the first step in benchmarking, but the competitive benchmarks have already been developed and presented 
above. One could certainly generate last year's numbers for comparison with the competitive benchmarks. In this case, how does your operation compare to the competition? For additional insight, look at several years of data. What conditions were present during the good years; what happened during the bad years? One could also, perhaps, break it down further by months and seasons. Such a process could then provide top-level baseline metrics for the plant.

To utilize such benchmarking results, a recommendation would be to first determine your goals for the process. In the research cited in this paper, information on many more parameters was collected, but not developed as benchmarks. Indeed only three benchmarks were presented. From this abbreviated benchmarking process, obvious goals might be to reduce required manhours, increase efficiency, and improve online time. To operationalize this to one's setting, you could, for example, write a memo: "Increase efficiency, improve online time, and layoff 20 percent of the staff!" Since this approach may not produce the desired results, a backup plan should be developed. The plan should be specific to your situation. The goals should be meaningful, clearly defined, and achie vable within a specified time period. In a continuous improvement process all aspects of the operation should be addressed

As this is the authors' first attempt to consider the application of benchmarking theory to FBC plants, one would hesitate to draw too definitive a set of conclusions from the analyzed results. However, the literature reviewed and cited in this research paper and the three example benchmarks developed seemed to point out the applicability of benchmarking to this type of combustion technology. One would anticipate being able to develop some extremely valuable information for practitioners and researchers in atmospheric fluidized bed combustion technology through the use of benchmarking. It is recommended that additional benchmarks be developed for this industry, as well as collecting and analyzing performance data for follow-on years.

The process of generating appropriate performance benchmarks for AFB plants is still in its formative stages. However, one would believe that this type of information would be extremely valuable for companies within the AFB industry. This conclusion was determined based on the very positive response received by the authors while presenting certain of these results at a national energy conference.

The authors acknowledge financial support from the National Energy Technology Center (NETL) - Morgantown in developing this research. All conclusions are the authors' and should not be attributed to the sponsoring agency.

\section{References}

1. Ammons, D. A Proper Mentality for Benchmarking. Public Administration Review. Vol. 59, no. 2, March/April 1999.

2. $\quad$ Anderson, J. Trade Restrictive Benchmarks. Economic Journal. Vol. 108, no. 449, July 1998.

3. Baker, B. Do It Right the Second Time: Benchmarking Best Practices in the Quality Change Process. Quality Progress. Vol. 31, no. 5, May 1998.

4. Balm, G. Benchmarking: A Practitioner's Guide for Becoming and Staying Best of the Best. QPMA Press. 1992.

5. $\quad$ Biesada, A. Benchmarking. Financial World. Sept. 1991.

6. Biesada, A. Strategic Benchmarking. Financial World. Sept. 1992.

7. Bogan, C. and M. English. Benchmarking For Best Practices: Winning Through Innovative Adaptation. McGraw-Hill, 1994.

8. $\quad$ Camp, R. Best Practice Benchmarking. CMA Magazine. Vol. 72, no. 8, July/August 1998.

9. Campbell, A. Tailored, Not Benchmarked. Harvard Business Review. Vol. 77, no. 2, March/April 1999.

10. Cox, A. and I. Thompson. On the Appropriateness of Benchmarking. Journal of General Management. Vol. 23, no. 3, Spring 1998.

11. Cox, J., L. Mann, and D. Samson. Benchmarking as a Mixed Metaphor: Disentangling Assumptions of Competition and Collaboration. Journal of Management Studies. Vol. 34, no. 2, March 1997.

12. Das, T. Benchmarking: Theory and Practice. IIE Transactions. Vol. 30, no. 9, Sept. 1999.

13. Davies, P. Perspectives: Benchmarking. Total Quality Management. Dec. 1990.

14. Day, C. Benchmarking's First Law: Know Thyself! Industry Week. Feb. 1992. 
15. Dunn, R. Basic Guide to Maintenance Benchmarking. Plant Engineering. Vol. 53, no. 1, Jan. 1999.

16. Elmuti, D. The Perceived Impact of the Benchmarking Process on Organizational Effectiveness. Production \& Inventory Management Journal. Vol. 39, no. 3, 1998. 17.

17. Elmuti, D., Y. Kathawala, and S. Lloyd. The Benchmarking Process: Assessing Its Value and Limitations. Industrial Management. Vol. 39, no. 4, July/August 1997.

18. Eyrich, H. Benchmarking to Become Best of Breed. Manufacturing Systems. April 1991.

19. Fitz-enz, J. Benchmarking Best Practices. Canadian Business Review. Vol. 19, no. 4, 1992.

20. Fong, S. and E. Cheng. Benchmarking: A General Reading for Management Practitioners. Management Decision. Vol. 36, no. 5/6, 1998.

21. Fuller, J. and F. Scherr. AFBC Performance Benchmarking. Industrial Energy Systems Forum Proceedings. 1998.

22. Henricks, M. How Do You Measure Up? Small Business Reports. June 1993.

23. Jackman, J. Modeling Techniques for Business Process Re-engineering and Benchmarking. IIE Transactions. Vol. 30, no. 10, Oct. 1998.

24. Main, J. How to Steal the Best Ideas Around. Fortune. Oct. 1992.

25. McGonagle, J. and D. Fleming. Options in Benchmarking. Quality Progress. Vol. 31, no 2, Feb. 1998.

26. McNair, C. and K. Leibfried. Benchmarking: A Tool For Continuous Improvement. Wiley, 1992.

27. Murray, M., R. Zimmernann, and D. Flaherty. Can Benchmarking Give You a Competitive Edge? Management Accounting. Vol. 79, no. 2, Aug. 1997.

28. O'Mara, D. Benchmarking for Profit. Security Distributing \& Marketing. Vol. 29, no. 3, Feb. 1999.

29. Puckett III, J. and P. Seigel. Looking in the Mirror. Journal of Business Strategy. Vol. 18, no. 3, May/June 1997.

30. Quality and Productivity Management Association. Benchmarking, The IBM-Rochester Way. Commitment Plus. Vol. 66, no. 12, Aug. 1991.

31. Ransley, D. Training Managers to Benchmark. Planning Review. Vol. 21, no. 1, Jan./Feb. 1993.

32. Schwartz, K. Benchmarking for Dollars. Datamation. Vol. 44, no. 2, Feb. 1998.

33. Sheridan, J. Where Benchmarkers Go Wrong. Industry Week. March 1993.

34. Vaziri, H. Questions to Answer Before Benchmarking. Planning Preview. Vol. 21, no. 1, Jan./Feb. 1993.

35. Waston, G. Benchmarking: Up-Front Preparation and Strategic Perspective Lead to Benchmarking Success. Productivity. Vol. 12, no. 9, Sept. 1991. 
Attachment 1

Chart 1

Number FTE Staff Per Million MWH
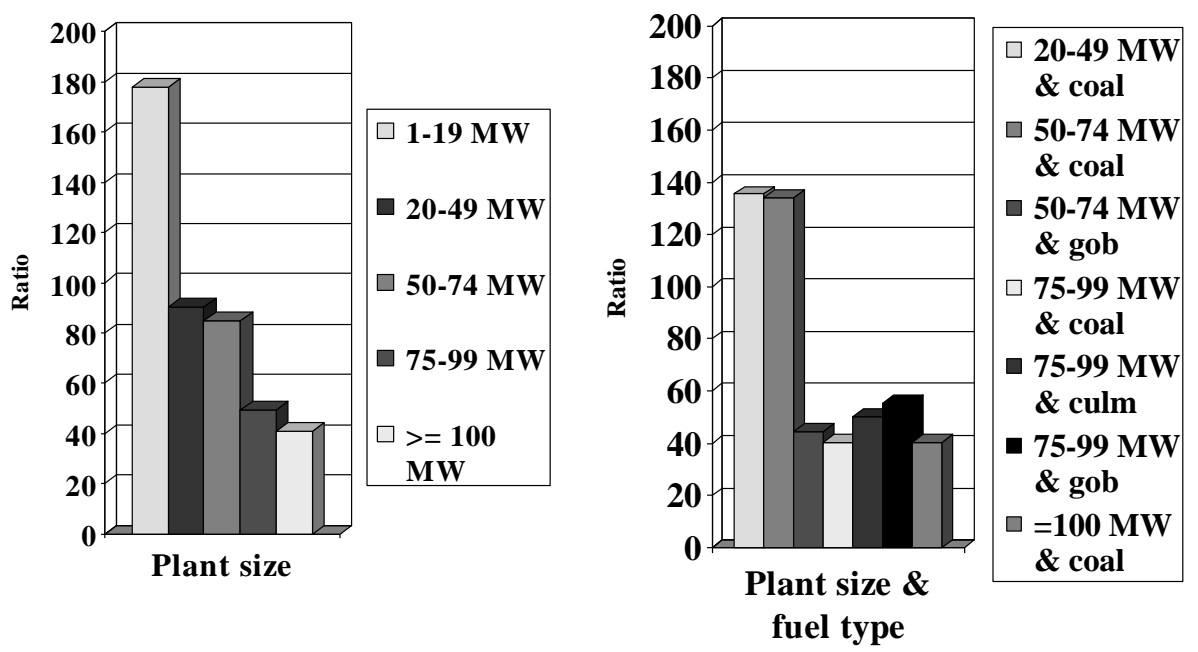

\section{Chart 2}

\section{Total Gross Plant Efficiency}
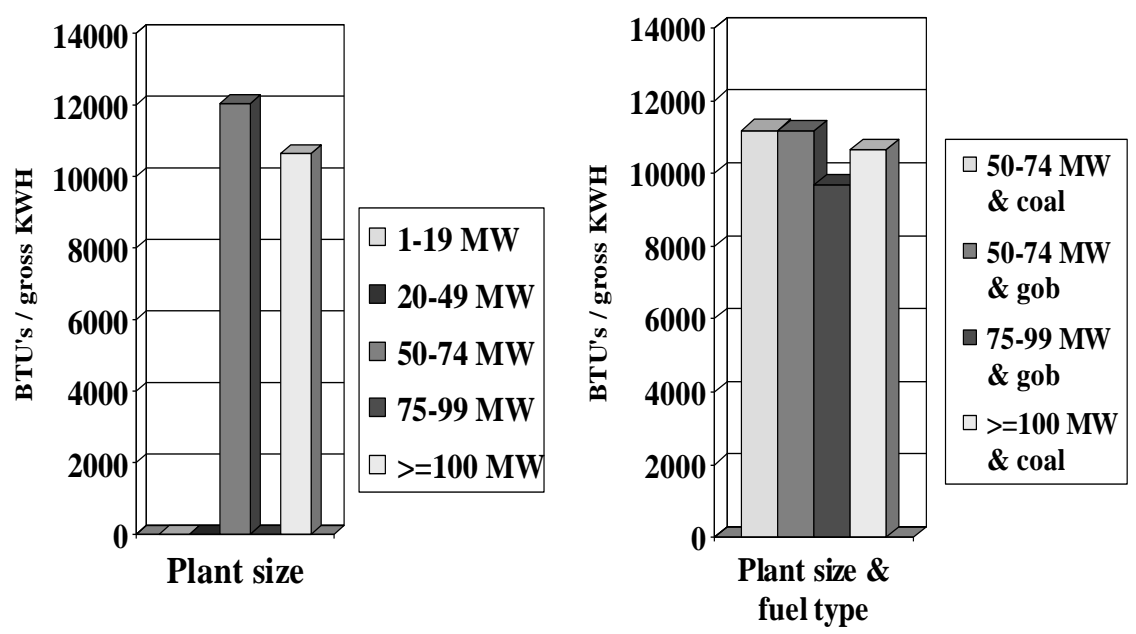


\section{Chart 3}

\section{Percent Of Time On-line in 1998}
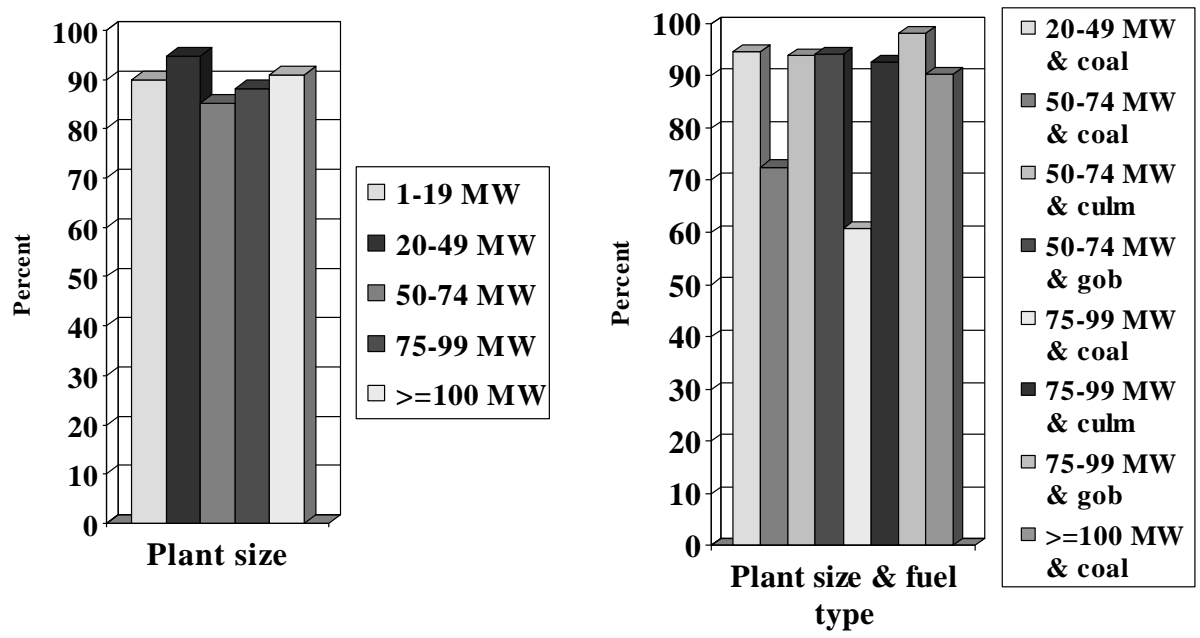
Notes 